\title{
TRES RAZONES PARA LA UTILIZACIÓN DE LA EFICIENCIA EN EL DERECHO PROCESAL CONCURSAL
}

\section{THREE REASONS TO UTILIZATION THE EFFICIENCY ON BANKRUPTCY PROCEDURAL LAW}

Nicolás Ignacio Ariel Carrasco Delgado*

Resumen

En este artículo exploro tres razones por las cuales el Derecho Procesal Concursal es uno de los subconjuntos normativos donde tienen aplicación las consideraciones de eficiencia del análisis económico del Derecho. Para tal efecto, nos centraremos en el examen de las necesidades de pago de créditos que originan un procedimiento concursal. Al respecto, el Derecho Procesal Concursal buscará incrementar la riqueza existente con miras a satisfacer esas necesidades. En ese contexto, el Derecho Procesal Concursal posee una serie de instrumentos que persiguen incrementar la masa activa; asimismo, respeta en lo indispensable las reglas de titularidad de créditos (en lo necesario para enfrentar el problema de acción colectiva de los acreedores que surge con la insolvencia) y, finalmente, permite justificar la eficiencia en las preferencias de los mismos sujetos participantes del procedimiento concursal.

Palabras claves: Derecho Concursal, Derecho Procesal, análisis económico del Derecho.

\footnotetext{
* Abogado. Licenciado en Ciencias Jurídicas y Sociales de la Universidad de Chile. Magíster con mención en Derecho Económico de la Universidad de Chile. Doctorando en Derecho de la Universidad Autónoma de Madrid. Becario de Becas Chile para cursar estudios de doctorado en el extranjero, 2015. Profesor asistente de Derecho Procesal de la Universidad de Chile. Dirección postal: Pío Nono No 1, Providencia, Santiago. Correo electrónico: ncarrascod@gmail.com. Artículo recibido el 9 de febrero de 2017 y aceptado para su publicación el 18 de diciembre de 2017.
} 


\begin{abstract}
In this article, I shall explore three reasons why Bankruptcy Procedural Law is one of the normative subsets in which the considerations of efficiency in economic analysis of law are applied. To that end, I shall concentrate on the examination of the need to pay outstanding debt obligations which results from bankruptcy proceedings. With regards to this, bankruptcy procedural law seeks to increase existing wealth in order to satisfy these needs. In this context, bankruptcy procedural law avails of a series of instruments which seek to increase the debt pool; likewise and where essential, it observes the rules of receivables (only where necessary to deal with the problem of collective proceedings on the part of creditors in which insolvency can result), and finally, it allows the justification of efficiency in the preferences of those who participate in bankruptcy proceedings.
\end{abstract}

Key-words: Bankruptcy law, procedural law, economic analysis of law.

\title{
I. INTRODUCCIÓN
}

56 Desde el punto del bienestar social el objetivo del Derecho Procesal Concursal corresponde a la denominada eficiencia concursal ex post ${ }^{1}$. Tal finalidad implica que el proceso concursal busca mejorar la tasa de recuperación de créditos ${ }^{2}$. De esta forma, este objetivo se cumplirá cuando la tasa de recuperación de créditos existente al término del concurso sea mayor que la tasa de recuperación de créditos que pudieran haber recibido los acreedores a su inicio. Al respecto, los acreedores son considerados como un todo ${ }^{3}$. Lo señalado implica reconocer un objetivo de eficiencia

\footnotetext{
${ }^{1}$ La literatura del análisis económico del Derecho Concursal distingue entre eficiencia concursal ex ante y ex post. La primera refiere una serie de efectos que la ley de insolvencia produce entre acreedores y deudores en periodos de solvencia de este último (efecto de incentivos sobre el deudor para cumplir sus obligaciones; efecto de incentivos sobre el deudor para el inicio oportuno del concurso, y efecto de incentivos sobre los acreedores para fiscalizar al deudor). Al respecto, puede verse BERKOVITCH y IsRAEL (1999), pp. 347-377. Sin embargo, considero que una vez iniciado el concurso, solamente interesa la eficiencia concursal ex post, ya que ella se logrará en la medida que se aumente la tasa de recuperación en los procedimientos concursales. Dado que este artículo se enmarca en un estudio de Derecho Procesal Concursal es que nos centraremos en esa finalidad de eficiencia. De hecho, la eficiencia ex ante es estudiada preferentemente en las finanzas corporativas, véase WoHLSCHLEgel (2002), pp. 21-43.

${ }^{2}$ Cabrillo (1989), p. 45; Peinado (2006), p. 239; Marinc y Vlahu (2012), p. 10; SCHWARTZ (1998), p. 1815.

${ }^{3}$ JaCKSOn y ScOTt (1989), pp. 156-158.
} 
y no de justicia como sostienen algunos autores ${ }^{4}$. Sin embargo, no deseo entrar en una discusión de los fines del proceso concursal; en vez de ello, me propongo explorar si el Derecho Procesal Concursal es un subconjunto normativo donde se persigue incrementar la riqueza ${ }^{5}$. De ser así, entonces, la lógica en que opera la eficiencia concursal ex post sería apropiada en ese subconjunto normativo. En efecto, la eficiencia concursal ex post es lo que permite tratar a los acreedores de modo que jurídica y económicamente logren una mayor satisfacción crediticia.

\section{LAS NECESIDADES DE CRÉDITO INSATISFECHAS Y LAS VÍAS PARA AFRONTARLA}

Para poder aproximarnos a esta materia comenzaremos asumiendo que la riqueza social es todo aquello que existe en una sociedad y que es suscep-

${ }^{4}$ En la doctrina estadounidense podemos mencionar lo sostenido por Elizabeth Warren para quien la legislación concursal debe establecer un conjunto particular de reglas que determinen maneras de soportar las pérdidas generadas por el incumplimiento de un deudor, véase WARREN (1987), pp. 775-814. También se ha sostenido que la normativa concursal involucra y da espacio a la expresión de diversos intereses y valores diversos de la eficiencia, véase KorobKin (1993), pp. 757-777. Esto último puede ser efectivo, ya que cuando se señala que la finalidad primordial del concurso es la eficiencia concursal ex post, ello no significa que no existan otros fines que adquieren protección en ese subconjunto normativo. Con todo, es esa finalidad de eficiencia la que permite dar sentido a las reglas concursales en su generalidad. En este artículo se trata de explicar tres razones que permiten comprender esa coherencia normativa que imprime la eficiencia frente a necesidades insatisfechas de crédito (aquello que origina el concurso). En la doctrina nacional el autor que ha discutido que la eficiencia sea una de las finalidades del Derecho Concursal corresponde a Juan Luis Goldenberg, puede verse Goldenberg (2013a), p. 35 y Goldenderg (2013b) 350 y 351.

${ }^{5}$ Esta afirmación se sostiene en el hecho de que el concurso es una institución de naturaleza procesal. De ahí la referencia en este artículo al Derecho Procesal Concursal. La explicación fundamental es que los efectos propios del concurso solamente surgen cuando existe un procedimiento concursal propiamente tal o, bien, una salida preventiva a la insolvencia (la que habitualmente y con mayor o menos intensidad se rige por reglas de publicidad, oponibilidad y de mayoría que escapan del tratamiento sustantivo y del pleno respeto del principio de autonomía de la voluntad y efecto relativo de los contratos). Esas reglas procedimentales hacen surgir los efectos propios del concurso y dan origen a un estado jurídico nuevo, inexistente con anterioridad, véase Pérez Del Blanco (2007), pp. 19-41. Asimismo, el tratamiento procesal es el que permite explicar las necesidades de coordinación de múltiples clases de acreedores como se examinará en este artículo. Por último, no existe estado jurídico sustantivo de insolvencia o cese de pago de obligaciones que conduzca necesariamente al concurso. La existencia de la alternativa de ejecución individual establece que de concurrir ese estado jurídico sustantivo pudiera ser razonable para acreedores y deudores (por lo menos en la regulación nacional) que exista indistintamente ejecución individual, concurso, o ninguna de ellas. A favor de esta explicación, CARrasco (2016a), pp. 185-189; en contra Concha (1971), pp. 10-52. 
tible de una apreciación pecuniaria ${ }^{6}$. Una de las finalidades de la riqueza es satisfacer necesidades. Cuando nos enfrentamos al Derecho Concursal, la necesidad insatisfecha es la falta de pago de crédito cualquiera sea su origen (comercial, financiero, laboral, etc.). Así, cada uno de los reclamos formulados por los acreedores puede ser transformado en una valoración pecuniaria (masa pasiva). Entonces, podemos perfectamente señalar que el conjunto de los reclamos monetarios que existen en contra del deudor constituyen necesidades de pago que no pueden ser solucionadas con la riqueza conformada por el patrimonio del deudor, ya sea porque los activos circulantes de esa riqueza son inferiores a los créditos (iliquidez) o, bien, debido a que la valoración de los activos es inferior al pasivo exigible (insolvencia).

Enfrentados a tal realidad, los acreedores querrán mejorar sus probabilidades de pago. Para llegar a esta conclusión no se necesita ser un ortodoxo de la racionalidad económica. Basta simplemente aceptar que en materia de necesidades insatisfechas de crédito, cualquier persona buscará reducirlas al máximo ${ }^{7}$. Por tanto, desde ya debe quedar claro que se trata de valoraciones crediticias, siendo difícil aventurar la concurrencia de valoraciones de otro tipo. Como consecuencia, no estamos persiguiendo eliminar necesidades monetarias insatisfechas dejando de lado aspectos de justicia o equidad. Se trata, simplemente, de buscar la manera en que sea menor el no pago. Para ello se requiere, indudablemente, incrementar el patrimonio del deudor.

Es en ese escenario donde interviene el Derecho Procesal Concursal. De las opiniones mencionadas a favor de la finalidad de eficiencia concursal ex post, queda en evidencia que el concurso es una mejor respuesta para reducir la magnitud de las necesidades insatisfechas de crédito, en comparación con la vía de la tutela individual ${ }^{8}$. Lo anterior, incluso, sin manifestar preferencia alguna por el concurso entendido como un instrumento legal obligatorio ${ }^{9}$, o bien, como uno de base contractual ${ }^{10}$. En

${ }^{6}$ Posner (1999), pp. 17-18.

${ }^{7}$ Con todo, si una persona es adversa al riesgo pudiera obtener un resultado cierto en el concurso que signifique una recuperación menor de la que pudiera corresponderle con una actuación litigante más riesgosa y agresiva, véase KAHNEMAN y TVERSKY (1984), pp. 341-342.

8 "El procedimiento concursal básico está diseñado para corregir el problema del common pools. La clave para la implementación efectiva de esta meta es estimular el concurso única y exclusivamente cuando es del interés de los acreedores como grupo (...)”. Traducción del autor, en su lengua original: "Bankruptc's basic procedure are designed to ameliorate a common pool problem. The key to effective implementation of this goal is to trigger bankruptcy when, and only when, it is in the interest of creditors as a group" JACKSON (1985), p. 26

${ }^{9}$ Warren y Westbrook (2005), pp. 1197-1254

${ }^{10}$ Puede verse Adler y Ayres (2001-2002), pp. 83-150; Schwartz (1998), pp. 1807-1851. 
ambos casos, los autores de Derecho Concursal buscan exactamente lo mismo: Establecer la mejor manera regulatoria (vía heterónoma legal o vía consensual) para reducir las necesidades insatisfechas de crédito de los acreedores. Para estos efectos, deviene en indiferente la fuente de donde provenga la regulación.

Ahora bien, subyace en tales autores el consenso que la tutela individual conduce a resultados no deseables. Por ejemplo, en un régimen sin concurso y donde no existan acreedores privilegiados, se pagarán solamente aquellos acreedores que demanden y realicen los bienes de manera más rápida, dando con ello aplicación al principio prior tempore, potior iure (que se encuentra en la base de la tutela ejecutiva individual). Tal resultado puede justificarse en un premio a la diligencia del acreedor que ejecuta tempranamente a su deudor.

Esto permite sostener que si el legislador solo se interesara en proteger el interés privado del acreedor más diligente en demandar, entonces, no existiría legislación concursal. Sin embargo, tal legislación existe en todas las sociedades que han alcanzado cierto nivel de complejidad en sus relaciones financieras, comerciales, económicas o crediticias ${ }^{11}$. Por tanto, es algo evidente que la presencia de una legislación concursal manifiesta que la solución proveniente del principio prior tempore, potior iure, no es la única que satisface el interés social en presencia de necesidades de crédito insatisfechas. La legislación concursal expresa la necesidad de colectivización de la actuación de los acreedores enfrentados a la insatisfacción de sus necesidades crediticias, más allá que entre ellos existan diferencias ${ }^{12}$. Ya no basta el principio del prior tempore, potior iure, sino que adquiere sentido un accionar colectivo ${ }^{13}$, donde se requiere concurrir o verificar los créditos insatisfechos en las oportunidades que la legislación establezca, no siendo indispensable ser el primero ${ }^{14}$.

Lo expuesto se concretiza en la idea que el accionar colectivo busca una mejora en la satisfacción de los acreedores como un todo ${ }^{15}$. El proce-

${ }^{11}$ Existen trabajos donde se han examinado diferentes sistemas concursales en países de la cultura occidental y oriental, encontrando en cada uno de ellos procedimientos de liquidación y reorganización o, bien, mecanismos procedimentales similares a ellos, puede verse ARmstrong y Riddick (2003), pp. 1-44; LA PORTA et al. (1998), pp. 1113-1155.

${ }^{12}$ Originadas por la cuantía de sus créditos, de su origen, del título que los habilita para participar o, bien, de las garantías que poseen establecidas a su favor.

${ }^{13}$ JACKSON (1985), pp. 8-24.

${ }^{14}$ Este proceso en que los acreedores concurren a hacer valer sus acreencias en la masa concursada, se denomina “determinación del pasivo" y se encuentra regulada en lo referente al procedimiento concursal de reorganización en los arts. 70 a 76 de la ley $\mathrm{N}^{\circ} 20.720$, de 2014 y en lo referente al procedimiento concursal de liquidación en los arts. 170 a 179 de la ley $\mathrm{N}^{\mathrm{o}} 20.720$, de 2014.

${ }^{15}$ En la legislación española véase GonZÁLEz (2005), pp. 305-306. 
dimiento concursal se erige como la solución institucional legal o convencional para esa mayor satisfacción, y no uno basado en el principio prior tempore, potior iure ${ }^{16}$. Esta primera idea, que vincula el accionar colectivo como una pretensión de mejora del estado de los acreedores agrupados como un todo, será denominada en lo sucesivo como "idea de satisfacción del colectivo crediticio".

Ahora bien, los procedimientos civiles (los juicios de tutela individual y colectiva) poseen como principio dogmático su carácter dispositivo ${ }^{17}$. Tal principio se manifiesta en que el inicio de los procedimientos queda entregado a la decisión de los sujetos activos (nemo iudex sine actore). Tal expresión procesal refleja que la decisión de incoar un procedimiento se delega por el Estado a los particulares, de forma que los órganos jurisdiccionales solamente actuarán a petición de parte. Serán ellos valorando las consideraciones concretas del caso, y los factores que consideren apropiados (sean monetarios, de venganza privada, de altruismo, u otros) los que tomarán la decisión de demandar. El principio dispositivo descansa en la libre valoración de los sujetos para perseguir su propio interés ${ }^{18}$.

Pues bien, en pleno respeto del principio dispositivo es que el legislador mantiene los procedimientos de tutela individual a pesar de que la solución concursal es la vía más adecuada e idónea para afrontar las necesidades insatisfechas de crédito. En otras palabras, la idea de satisfacción del colectivo crediticio no se traduce en una imposición procedimental para afrontar las dificultades que expresa. Por el contrario, subsisten las vías de tutela individual y colectiva, regulando cada país los incentivos para que los particulares inicien una u otra alternativa, dependiendo de sus intereses. Lo que se desea expresar es que en respeto del principio dispositivo se consagran opciones diversas para que los particulares resguarden sus intereses, incluyendo los crediticios insatisfechos. De esta forma, a pesar de que el legislador pudiera considerar que la idea de satisfacción del colectivo crediticio se resuelve de forma apropiada por la normativa concursal, de todas formas, deja en manos de los interesados la

${ }^{16}$ Esto no impide considerar que en ciertos casos un procedimiento individual pudiera alcanzar esa mayor satisfacción. Al respecto puede verse VeIGA (2013), pp. 67-68.

${ }^{17}$ Hunter (2010), pp. 149-188.

${ }^{18}$ Tal idea de racionalidad ha tenido una evolución completamente desligada del análisis económico del Derecho, y no se detectan críticas al el fundamento de racionalidad involucrado en el principio dispositivo, sobre la base de consideraciones de fallas de mercado que imposibiliten el libre juicio de los interesados para proteger de mejor manera sus intereses. Con todo, esas críticas arrecian a la idea de racionalidad de eficiencia asociada a la perspectiva normativa del law and economics. Sobre una aguda crítica a la idea de racionalidad de las teorías económicas normativas, puede verse ElSTER (2009), pp. 3-10 y Hirschman (1986), pp. 77-82. 
decisión concreta respecto de si tal normativa resguarda de mejor manera sus intereses ${ }^{19}$. Así, pudiera ser que todos los acreedores no den inicio a un concurso ${ }^{20}$, concurriendo o no acuerdo previo entre ellos, a pesar de que tal situación sea la más óptima desde una perspectiva de eficiencia ${ }^{21}$ El principio dispositivo también rigen en procedimientos de preconcurso cuya finalidad es anticipar los riesgos de insolvencia ${ }^{22}$. Tales mecanismos se estructuran sobre la decisión (fundamentalmente) del deudor para su inicio ${ }^{23}$.

Con lo señalado queda en evidencia que la idea que subyace al principio dispositivo no es afectado por las exigencias de eficiencia que pudieran tener los autores del análisis económico del Derecho, o lo que pudiera considerar un legislador racional, o aquello que pudiera emanar de un dictado económico que idealmente favoreciera la opción concursal. El principio dispositivo, con la racionalidad que lo subyace, sigue

${ }^{19}$ Con todo, ciertas legislaciones establecen penalizaciones en caso que no se de inicio al concurso dentro de cierto plazo. Esas penalizaciones afectan normalmente al deudor y atemperan la vigencia del principio dispositivo. Ejemplos de estas regulaciones encontramos en los arts. 15(a)(4) y 15(a)(5) en la Insolvenzordung de Alemania. En la legislación española se contemplan situaciones donde se atempera el principio dispositivo en los arts. 5.1 y 5 bis. 5 de la ley 22/2003, de 9 de julio.

${ }^{20} \mathrm{Se}$ considera que para favorecer el pronto inicio del concurso se deben reducir las exigencias normativas asociados a los presupuestos objetivos. Es relevante considerar que la tasa de recuperación se encuentra relacionada con el pronto inicio (a más pronto inicio mayor tasa de recuperación), véase Bisogno y De Luca (2014), p. 20. Por ello, se considera que el presupuesto del concurso debería ser el cese de pagos (como ocurre en el art. $117.1^{\circ}$ ley $\mathrm{N}^{\circ} 20.720$, de 2014 ) y el riesgo de cese de pagos en el preconcurso.

${ }^{21}$ Esta situación no óptima es generada porque una solución óptima solamente existirá cuando haya perfecta información acerca de la situación y preferencias de los otros. Tal marco informacional no siempre está disponible, véase ELSTER (1997), p. 54.

${ }^{22}$ La Propuesta de Directiva del Parlamento Europeo y del Consejo "Sobre marcos de reestructuración preventiva, segunda oportunidad y medidas para aumentar la eficacia de los procedimientos de condonación, insolvencia y reestructuración, y por la que se modifique la Directiva 2012/30/UE” [COM (2016) 723 final; 2016/0359 (COD)], señala en su art. 1 a) que los procedimientos de reestructuración preventivos deberán estar contemplados para casos de "riesgo de insolvencia"; su art. 3 dispone que los mecanismos de alerta rápida se deben considerar en caso de "deterioro de la actividad empresarial"; por su parte, el art. 4 establece que la disponibilidad de marcos de reestructuración preventiva debe existir cuando exista "riesgo de insolvencia"; el art. 55 refiere a "probabilidad de insolvencia" etc. Cabe señalar que para dar contenido a esos conceptos (no definidos en la propuesta de directiva) podemos mencionar las medidas prejudiciales concursales, máxime si esa regulación admite en su art. 4.2 que los marcos de reestructuración preventiva pueden consistir en uno o varios procedimientos o medidas. Para examinar una medida cautelar prejudicial en temas concursales, véase CARRASCO (2012), pp. 108-110.

${ }^{23}$ Arts. 3.1, 4.1 y 5 de la Propuesta de Directiva del Parlamento Europeo y del Consejo "Sobre marcos de reestructuración preventiva..., op. cit. 
rigiendo más allá de cuál sea la opción preferida en el contexto de la idea de la satisfacción del colectivo crediticio. Entonces, sabiendo que el legislador contempla diferentes alternativas procedimentales para enfrentar la existencia de necesidades de crédito insatisfechas y que la opción por alguna de esas alternativas dependerá de la elección de los interesados, la cuestión que surge es indagar si el Derecho Procesal Concursal busca mejorar la riqueza a la que se enfrentan los acreedores (valor del patrimonio del deudor al momento del inicio del concurso), esto es, si es efectivo que el Derecho Procesal Concursal pretende incrementar la valoración del patrimonio del deudor para disminuir la magnitud de las necesidades crediticias insatisfechas. De responderse afirmativamente tal asunto, entonces, la eficiencia sí tendría un valor en el contexto del Derecho Procesal Concursal.

En lo que sigue se expondrán las razones por las que sostengo que la eficiencia es un valor presente en el Derecho Procesal Concursal. Entenderemos por eficiencia la mejora en la capacidad de pago del patrimonio del deudor a fin de reducir las necesidades crediticias insatisfechas de sus acreedores, considerando a estos últimos como un todo ${ }^{24}$. Dos aclaraciones previas. La primera, es que cuando hablamos de eficiencia como mejora de la capacidad del patrimonio del deudor para pagar a sus acreedores, no nos estamos refiriendo al criterio de maximización de la riqueza de Richard Posner ${ }^{25}$, sino que nos remitimos al criterio Kaldor-Hicks ${ }^{26}$. Este último criterio de eficiencia es el que permite fundar decisiones que incrementen el nivel de riqueza existente ${ }^{27}$, incluso, existiendo ganadores y perdedores (como en todo contexto procesal).

La segunda aclaración refiere a que la maximización de la capacidad de pago del patrimonio del deudor comprende la necesidad de reducir las insatisfacciones crediticias de los acreedores como un todo. Este aspecto, ha sido debidamente considerado por la literatura especializada. En este sentido, la virtud de la legislación concursal tendente a tratar las acreencias de todos los acreedores en un determinado curso de acción común ha sido referida desde comienzos de la década de 1980 por Michelle White ${ }^{28}$ y por James Ang y Jess Chau ${ }^{29}$. Asimismo, Thomas Jackson señala que la

${ }^{24}$ Esto es, incluso, aceptado por autores que sostienen una posición contractualista como Pulgar (2013), p. 15, donde expresa que la diferencia entre la visión contractualista y judicial del concurso se basa en que en esta última visión existe un tratamiento de los acreedores como un colectivo.

${ }^{25}$ Posner (1997), p. 11 y ss.

${ }^{26}$ Kaldor (1939), pp. 549-552

${ }^{27}$ Eremenko (2005), pp. 3-6.

${ }^{28}$ White (1980), pp. 550-564.

${ }^{29}$ ANg y Chua (1980), pp. 355-359. 
acción colectiva de los acreedores comprende la satisfacción de los acreedores en su conjunto ${ }^{30,31}$, para luego sostener con Scott que la finalidad de la reorganización es asegurar que los activos sean destinados al mejor uso para todos los acreedores ${ }^{32}$. También, Douglas Baird, para quien la definición de un procedimiento concursal supone una acción que busca mejorar a más de un sujeto ${ }^{33}$.

Con tales aclaraciones previas, las razones por las que sostenemos que la eficiencia se encuentra reconocida en el Derecho Procesal Concursal son las siguientes:

i) El Derecho Procesal Concursal posee una serie de instrumentos que persiguen precisamente mejorar la tasa de recuperación de los acreedores y que no se encuentran presentes en otras vías procedimentales;

ii) El Derecho Procesal Concursal no cuestiona las reglas de titularidad de derechos sino en lo indispensable. De esta forma, los potenciales perdedores no emanan de decisiones concursales de juego de suma cero. Por el contrario, las decisiones concursales ayudan a reducir la existencia de perdedores y

iii) El Derecho Procesal Concursal constituye un foro de decisión donde es factible justificar la eficiencia en las preferencias de los sujetos que participan en el concurso.

\section{Los instrumento del Derecho Procesal Concursal PARA MEJORAR LA TASA DE RECUPERACIÓN DE CRÉDITOS}

La primera razón encuentra su reconocimiento en una serie de instrumentos procesales que persiguen la finalidad de incrementar la tasa de recuperación de créditos. Tales instrumentos procesales no existen en las alternativas procedimentales al concurso. De esta forma, es posible trazar

${ }^{30}$ JACKSON (1985), p. 12.

${ }^{31}$ En el Derecho español en sentido similar se pronuncia Aurelio Gurrea, cuando señala: "Hay que tener en cuenta los problemas derivados de la denominada acción colectiva, es decir, los problemas (o costes) derivados de actuar de manera conjunta como mejor convenga a los intereses de la colectividad de los acreedores" GURREA (2014), p. 843.

${ }^{32}$ JaCKSON y SCOTt (1989), pp. 156-158.

${ }^{33}$ BAIRd (1987), p. 824. En el mismo sentido, Stanley Longhofer y Stephen Peters son explícitos: "Nosotros nos proponemos que la quiebra existe para resolver un conflicto que surge para resolver el conflicto entre los acreedores cuando el deudor llega a ser insolvente. En la ausencia de un sistema concursal, los acreedores generalmente encuentran remedios privados a la reunión de deuda individual, incluso cuando una liquidación coordinada debería maximizar el valor a ser distribuido a los acreedores como un grupo". LONGHOFER y Peters (2004), pp. 249-250. 
una clara diferencia entre la tutela individual y la colectiva, en cuanto a que esta última posee una estructura encaminada hacia la eficiencia concursal ex post. El detalle de los instrumentos procesales excede el tratamiento de este artículo. Con todo, nos concentraremos en tres ejemplos.

Primeramente, la especialización de los jueces concursales es una clara muestra de la importancia que se asigna a la generación de una mejora en la tasa de recuperación ${ }^{34}$. En este sentido, la legislación española ha contemplado jueces en lo mercantil con competencia en temas concursales. Asimismo, en la legislación concursal chilena los jueces que conocen mayor cantidad de juicios concursales deben cursar cursos de especialización. La idea detrás de la especialización es reducir los costos del error concursal ${ }^{35}$, aminorar los costos concursales directos e indirectos (en lo que sea de incidencia las decisiones del juez ${ }^{36}$ ), y poder llevar a cabo una supervisión adecuada de la actividad de los otros órganos ${ }^{37}$. Tales fundamentos de la especialización coadyuvan a un aumento en la tasa de recuperación en la medida que la reducción de los costos trae consigo una disminución de la cantidad de recursos que remuneran a personas distintas de los acreedores o, bien, que impiden un correcto destino de la masa activa. Esta especialización judicial no existe en los jueces que conocen de la tutela individual; tampoco lo necesitan, ya que tales procedimientos suponen una tramitación bastante estandarizada. Además, existen economías de escala en la labor judicial asociadas a la alta cantidad de ingresos de esos procesos en el sistema de administración de justicia. Incluso, se puede afirmar que el carácter común de los jueces

${ }^{34}$ Este análisis de especialización no tiene relación con una política legislativa tendente a generar una primacía del juez sobre los directamente interesados en el concurso (deudor y acreedores). Más bien, corresponde a una regulación que pretende mejorar los niveles de corrección del sistema en todas las decisiones concursales, tengan o no relación con asuntos donde pudiera existir divergencia entre el juez y los directamente interesados.

${ }^{35}$ Se ha señalado que una de las grandes ventajas de la especialización es la capacidad de adoptar decisiones correctas en menor cantidad de tiempo, véase Voigt (2016), p. 191.

${ }^{36}$ La especialización reduce un conjunto de costos: costos del error; costos concursales directos (aquellos que tienen relación con los gastos que asumen los particulares y el Estado en el inicio y prosecución de un concurso), y costos concursales indirectos (aquellos que tienen relación con pérdidas de valor en los activos del deudor dado el concurso y con otros costos de oportunidad). Sin embargo, se traduce en un costo público de administración de justicia, consistente en el gasto necesario para el establecimiento de los tribunales especializados o de las reglas que tiendan a la formación especializada de los jueces. Indudablemente el objetivo de la especialización es que en esa ponderación la reducción de los dos primeros costos mencionados sea mayor que el aumento de los segundos. Esta lógica de necesidad de inversión en justicia nos aleja de un tratamiento de minimización de costos propio de las posiciones sustantivas del concurso (cercanos a la lógica de Coase) y nos conduce a un tratamiento de óptimo, puede verse CARrasco (2017), pp. 443-469.

${ }^{37}$ Puede verse art. 3 inc. final ley No 20.720, de 2014. 
que conocen de los procedimientos de tutela individual va asociado a una idea contraria a la especialización judicial en el concurso. En efecto, los jueces que resuelven juicios individuales no tienen interés en el nivel de la satisfacción crediticia de los demandantes, sino que ejercen su función con miras a garantizar el respeto de las etapas del consecutivo legal y decidir en definitiva (con prescindencia si su decisión alcanza tal objetivo de eficiencia). No se conocen normas procesales por medio de las cuales el juez común pueda incidir en los mecanismos de realización de activos optando por el que favorezca mayormente la recuperación.

Por otra parte, en el concurso existen funciones de dirección y administración que buscan mejorar las tasas de recuperación de créditos, las que recaen en ciertos órganos concursales. Así, la especialización en el concurso no solo existe en el órgano jurisdiccional sino que, también, en una serie de órganos concursales que participan en esos procedimientos. Las distintas legislaciones establecen entes técnicos altamente calificados para ejercer funciones de sustitución de la administración del deudor, o de fiscalización de tal administración ${ }^{38}$.

La lógica fundamental de los mencionados órganos es llevar a cabo labores de dirección en la ejecución o reorganización del patrimonio del deudor con miras a mejorar su capacidad de pago. En este sentido, las legislaciones buscan incentivar tal finalidad por medio de asociar la remuneración de los órganos mencionados al reparto que realicen a favor de los acreedores, de manera que a mayor reparto, mayor remuneración ${ }^{39}$. Estos órganos especializados no jurisdiccionales adoptan decisiones relevantes en el concurso. Así, en los procedimientos de liquidación serán ellos los

${ }^{38}$ Así ocurre en las distintas legislaciones. En este sentido, la especialidad de la administración concursal en España en la ley 22/2003, se contiene en su art. 27.3; en el caso alemán el administrador de la insolvencia es un órgano especializado en la gestión del ámbito de negocios específicos del deudor (sus requisitos se contienen en el art. 56 Insolvenzordung); finalmente, en el caso italiano el órgano especializado es el curador, estableciéndose una serie de requisitos en tal sentido en el art. 28 Legge fallimentare, de 1942.

${ }^{39}$ Así, por ejemplo, en Chile el art. 40 de la ley $N^{0} 20.720$, de 2014, establece una tabla de honorario único a pagar al liquidador a la fecha del reparto, la que se calculará sobre los ingresos que genere el respectivo procedimiento concursal. Por su parte, en la legislación estadounidense tanto en su capítulo 7 (referido al procedimiento de liquidación), como en su capítulo 11 (relativo a la reorganización), establecen que los trustees serán remunerados de acuerdo con ciertas estipulaciones normativas, usualmente una cantidad fija más alguna cantidad adicional dependiendo del tamaño del concurso. Las reglas que gobiernan esa remuneración se encuentran contempladas en el art. 330 Bankruptcy Code, y los límites legales a tales honorarios en el art. 326(a) Bankruptcy Code. Finalmente, en el sistema español el art. 34.1.2 de la ley 22/2003 establece las reglas a las que debe ajustarse el arancel de los administradores, dentro de las que se contempla la eficiencia. Para un examen crítico sobre el sistema español, puede verse Alonso (2016), pp. 72-73. 
que administren los bienes del fallido, adoptando medidas de continuidad de giro, realizando bienes, rindiendo cuentas, participando en el proceso de verificación de créditos, determinando la masa activa y pasiva del deudor, etc. Por su parte, en los procedimientos de reorganización ejercerán labores de coadministración o de supervisión de la actividad del deudor, y en todo caso, serán entes técnicos que emitirán información relevante e imparcial a los acreedores respecto del curso a seguir.

Las legislaciones no contemplan la existencia de estos órganos en los procedimientos de tutela individual. Tal como ocurre con la no especialización de los jueces que conocen de los referidos procedimientos, la inexistencia de órganos especializados se debe a que simplemente no son necesarios cuando existe un deudor y un acreedor enfrentados por el cobro de un crédito. El principio dispositivo dispondrá que el acreedor no necesita colaboración para la satisfacción de su propio interés; se encuentran ausentes en la tutela individual los problemas de coordinación que existen en el concurso. Tal como mencionamos, en las acciones de tutela individual no concurren mecanismos que tiendan a forzar la dirección de los actos ejecutados en el patrimonio del deudor hacia una mejora en la tasa de recuperación. Los demandantes y el juez deben solicitar y aprobar, respectivamente, aquellas vías de realización o utilización de activos del deudor que señale la ley. En cambio, los órganos concursales especializados poseen una serie de facultades discrecionales para elegir el mecanismo o curso de acción más apropiado a efectos de mejorar la valorización del activo. En aquellos casos donde esa facultad de dirección se encuentra limitada por la decisión de los acreedores, tal órgano técnico siempre tendrá la oportunidad de incidir en ellos. En este sentido, un órgano de administración concursal realizará una mala gestión (sujeta a responsabilidad civil y criminal, de acuerdo con la regulación nacional respectiva), si es que no informa o rechaza, sin ponderación alguna, la mejor propuesta de compra directa de activos del deudor o, bien, si lleva a cabo actos de licitación sin considerar debidamente las características del bien enajenado, en términos de equivocarse en someter la licitación a reglas de subastas no apropiadas ${ }^{40}$.

También los procedimientos concursales establecen opciones procedimentales para poder afrontar la situación de déficit patrimonial del deudor. En este sentido, habitualmente las legislaciones consagran dos clases de procedimientos generales, los de liquidación y los de reorganización. Incluso, la legislación alemana que posee un único curso procedimental

${ }^{40}$ Por ejemplo, si debiendo procederse, en atención a la naturaleza del bien, a una subasta holandesa se procede a una inglesa. Véase CARRASCO (2016b), pp. 355-364. 
permite la reestructuración en ciertos supuestos ${ }^{41}$. Una de las finalidades de tales alternativas concursales es que los partícipes del concurso elijan el mecanismo concursal que mejor satisfaga la tasa de recuperación de créditos. En consecuencia, se elegirá entre la liquidación o la reorganización, dependiendo de cuál vía mejore la eficiencia concursal ex post $t^{42}$. Así, si se dan los presupuestos de viabilidad e inviabilidad, entonces se optará correctamente para resguardar los intereses de los acreedores si en el primer supuesto se opta por la reorganización y, en el segundo, por la liquidación. Este aspecto ha sido considerado por la literatura concursal ${ }^{43}$. Dos regulaciones concretas demuestran esta finalidad. En el caso del Derecho Concursal chileno, a propósito de los procedimientos de reorganización judicial y del acuerdo de reorganización simplificado, el órgano concursal especializado denominado veedor, debe emitir un informe en que da cuenta, por una parte, del estado comparativo de recuperación que obtendrán los acreedores en caso de cumplirse la reorganización en cuestión y, por la otra, la cantidad que recibirían tales acreedores, en el

${ }^{41}$ Como ocurre con el denominado procedimiento Schutzschirmverfahren.

${ }^{42}$ Como crítica a la eficiencia se ha sostenido que el procedimiento reorganización es el ejemplo paradigmático de intervención de valores diversos a la eficiencia (consideraciones comunitarias, sociales, normas sociales e intuiciones morales). Gross (1997), pp. 14-24 y CARLSOn (1989), pp. 613-614, expresan que la explicación de eficiencia de la teoría de negociación de Thomas Jackson y Douglas Baird sucumbiría frente a esa realidad. Sin embargo, el hecho de que una reorganización dé lugar a consideraciones diversas del bienestar, no afecta la finalidad de eficiencia ex post. De hecho, la utilidad de esa eficiencia opera cuando se decide la continuidad del procedimiento por medio de una reorganización. Ello significa que en ese momento se valora que la recuperación de créditos será mayor que en un procedimiento de liquidación, incluso considerando todas esas cuestiones y valores diversos de la eficiencia. En otras palabras, la eficiencia concursal ex post anticipa e interioriza la repercusión que consideraciones diversas del bienestar pudieran surgir de una reorganización. Por tanto, si ese mecanismo es utilizado es porque conduce a una mejora en la eficiencia ex post superior a la liquidación a pesar del mayor costo que implica considerar esas otras consideraciones.

${ }^{43}$ Cornelli y Felli, señalan: "En términos más generales, cualquiera sea procedimiento adoptado (el deudor puede ser reorganizado, vendido en funcionamiento, liquidado por medio del desmantelamiento de sus activos), es razonable asumir que el objetivo común debería ser obtener el mayor valor total de los activos (más es preferido a menos). En este caso, el principal objetivo de la legislación (maximizar el valor de la firma insolvente) puede ser alcanzado por medio de una reducción de la demora y costos del procedimiento concursal". Traducción libre del autor, en su lengua original: "In more general terms, whatever procedure is adopted (the firm could be reorganized, sold as a going concern, liquidated through a dismantlement of its assets), it is reasonable to assume that the common objective should be obtaining the greatest total value (more is preferred to less). In this case, the main goal of the legislation (maximizing the value of an insolvent firm) can be reached through a reduction of the length and costs of a bankruptcy procedure" Bisogno y De LuCa (2014), p. 12. 
supuesto que los bienes de la empresa deudora fueran liquidados ${ }^{44}$. Tales escenarios son formulados por el veedor para que los acreedores adopten la decisión (liquidación o reorganización) que mejor convenga a sus intereses. Se trata de un informe que reduce las asimetrías de información entre el deudor y los acreedores; aminora los costos del error (al ser formulado de manera comparativa entre el cumplimiento del plan de reorganización o el valor de recupero vía liquidación), y persigue una mayor tasa de recuperación, ya que se presume que los acreedores, manteniendo constante los otros factores, optarán por aquella alternativa que conduzca a una mejora en la recuperación, considerando criterios de tiempo y monto.

La segunda normativa corresponde al caso del cramdown en el Derecho estadounidense, que permite al juez concursal imponer un acuerdo de reorganización a los acreedores disidentes. Dentro de la regulación que se establece en tal legislación, se contempla que el juez podrá imponer tal reorganización siempre que cada acreedor disidente afectado por el plan, tenga derecho a recibir pagos por un monto al menos equivalente al valor que hubiera correspondido a su crédito en un procedimiento de liquidación. Tal exigencia se contiene en el art. 1129(a)(7) Bankrupctcy Code, cuyo parámetro es la obtención del resultado más beneficioso para todos los acreedores (the best interest of creditors ${ }^{45}$.

Ese principio constituye un factor para examinar una reorganización racional (aquella que permite preservar el valor en funcionamiento de las empresas que enfrenten problemas de liquidez, pero que poseen un buen modelo de negocios), e impone una línea de base de protección a los acreedores que no consientan en la reorganización ${ }^{46}$. De esta forma, garantizándole la máxima recuperación posible a los acreedores disidentes, no se justifica su voluntad en contrario, imponiéndose el plan que permite igualar la eficiencia concursal ex post de la liquidación ${ }^{47}$. Esta concepción de permitir la aprobación de un plan de reorganización cuando iguala la tasa máxima de recuperación que obtendrían los disidentes en una liquidación, es lo que permite entender que en el Derecho Procesal Concursal concurren supuestos de responsividad no negativa, según veremos.

Ambos instrumentos permiten comparar el resultado esperado de dos procedimientos concursales con miras a forzar a los acreedores y al juez, respectivamente, a alcanzar la mayor tasa de recuperación crediticia. Tales mecanismos no existen en la tutela individual.

${ }^{44}$ Art. 57 No 8 y 107 de ley No 20.720, de 2014.

${ }^{45}$ NúÑEZ y OrTíz (2014), p. 153.

${ }^{46}$ Levitin (2012), pp. 1402; 1437-1438. Para una explicación de la evolución del criterio, véase Hicks (2005), pp. 820-841.

${ }^{47}$ Para un examen detallado acerca de la evolución normativa de la regulación que consagra el cramdown en la legislación estadounidense véase MARKELL (1991), pp. 74-103. 


\section{El Derecho Procesal Concursal no cuestiona las Reglas DE TITULARIDAD DE DERECHOS, SINO EN LO INDISPENSABLE}

La segunda razón para sostener el valor de la eficiencia en Derecho Procesal Concursal refiere a que en tal subconjunto normativo no se cuestionan, sino en lo indispensable, las reglas de titularidad de derechos configuradas por la legislación común ${ }^{48}$. En efecto, desde una perspectiva normativa sería deseable que la legislación concursal respete las exigencias de prioridad absoluta de los créditos. En este sentido, Oliver Hart ${ }^{49}$, María Carapeto ${ }^{50}$ y Lucian Bebchuck ${ }^{51}$. Lo anterior, incluso, a pesar de que existen opiniones encontradas a este respecto ${ }^{52}$. De todas formas, es posible afirmar que si la opción es un procedimiento duro según Povel (esto es, un procedimiento que respeta preferentemente los derechos de los acreedores por medio de garantizar el principio de prioridad absoluta), entonces, no habrá dudas acerca de lo deseable que resulta el respeto de las exigencias de preferencias que emanen de las normas de Derecho Común no concursal ${ }^{53}$. Con todo, también desde una perspectiva normativa, se ha sostenido que una de las características de una legislación concursal óptima es precisamente aquella que no establece en su regulación un tratamiento diferenciado de los derechos y titularidades que la legislación común otorga en las relaciones de crédito. En este sentido, nombre Baird ha sostenido que la problemática de cómo las pérdidas deben ser distribuidas no corresponde a un asunto de la legislación concursal, sino que ello compete a las reglas de titularidad de derechos de la ley común. Otra forma de entender la relación entre la ley concursal y la ley común en lo referente a los derechos crediticios supondría establecer tratamientos distintos para un mismo asunto de cobro ${ }^{54}$.

${ }^{48}$ Esta razón refuerza la naturaleza procesal del concurso porque considera las reglas de prelación como una cuestión de no concurso. Esas reglas operan una vez satisfecha la eficiencia concursal ex post (ya producida la mejora en la tasa de recuperación). Sirviendo solo para distribuir esa mejora entre los acreedores. Esa ubicación residual de las reglas de preferencia impide que tenga trascendencia en determinar la naturaleza jurídica del concurso.

${ }^{49}$ Hart (1995), pp. 105-107.

${ }^{50}$ Carapeto (2000), pp. 24-25.

${ }^{51}$ Bebchuck (2002), pp. 1-2.

${ }^{52}$ Berkovitch y Israel (1999), pp. 487-497; Gertner y Scharfstein (1991), pp. 12141215; BAIRD (1986), p. 135.

${ }^{53}$ Povel (1999), p. 668.

54 "No decimos quien debería soportar las pérdidas cuando una empresa incumple; no concebimos esto como una cuestión concursal. En nuestro trabajo sobre quiebras, hemos hablado solamente acerca del asunto que se mantiene después que uno decide como las pérdidas deberían ser distribuidas dado que consideramos esos asuntos como algo diferente 
$\mathrm{Si}$ analizamos este aspecto desde una perspectiva positiva, esto es, desde lo que sucede en la práctica, nos encontraremos con opiniones divergentes acerca de si la regla de prioridad absoluta es debidamente resguardada ${ }^{55}$. Pero esto no resulta complejo para el argumento que se viene dando en cuanto a que el Derecho Procesal Concursal resulta altamente indiferente respecto de la determinación de las titularidades de los acreedores, ya que, incluso, si se constatan violaciones a tales titularidades en el concurso, ello tampoco podría evitarse en un escenario previo. De hecho, existe una serie de actividades realizadas por el deudor en periodos de solvencia y que afectan las posibilidades de pago y preferencias de los acreedores. Así, el deudor puede realizar en el periodo previo a la insolvencia acciones de distribución de dividendos, sustitución de activos, inversiones no óptimas, y conductas dilusivas ${ }^{56}$. Por tanto, es difícil afirmar que la ley concursal genera instrumentos que conducen a vulnerar las reglas de preferencia, titularidad y cuantía de los créditos originados por normas de no concurso, si es que situaciones similares de infracción a tales reglas surgen en escenarios no concursales.

Lo anterior, nos permite concluir que lo relevante, desde una perspectiva positiva, es constatar que la legislación concursal no consagra mayores diferencias de tratamiento de los acreedores de aquellas que vienen establecidas por el Derecho Común.

Las excepciones a tal tratamiento (por ejemplo, ciertas reglas de mayor protección a los trabajadores o de recuperación preferentes de impues-

de los asuntos concursales” Traducción libre del autor, en su lengua original: “(...) do not say who should bear the loss when a firm fails; we do not conceive this as a bankruptcy question. In our work on bankruptcy, we have talked only about the issues that remain after one decides how losses should be distributed because we regard only these issues as distinct bankruptcy issues". BAIRD (1987), p. 823. "Cualquier valoración sobre los derechos de los acreedores privilegiados debería ser realizada fuera de la ley concursal. En el concurso, cualquier derecho que tengan los acreedores privilegiados en la legislación no concursal deberían ser respetados. La idea no es dar a ellos un buen trato, sino aproximar el mismo trato que ellos tienen fuera del concurso, de forma que ninguno tenga incentivos para comenzar un procedimiento concursal simplemente porque sus reglas distributivas son diferentes". Traducción libre del autor, en su lengua materna: "Whatever adjustments should be made to the rights of secured creditors should be made outside of bankruptcy law. In bankruptcy, whatever rights the secured creditors have under nonbankruptcy law should be respected. The idea is not to give them a good deal, but rather to approximate the same deal that they had outside of bankruptcy so that no one has an incentive to begin a bankruptcy proceeding simply because its distributional rule is different". BAIRD (1987), p. 832. En el mismo sentido véase JACKSON (1982), pp. 859-860.

${ }^{55}$ Hemos visto que existe diferencia de opinión respecto de si en el concurso se viola el principio de prioridad absoluta de créditos. Véase n. 40.

${ }^{56}$ Rasmussen (1994), p. 1168. 
$\left.\operatorname{tos}^{57}\right)$, son precisamente situaciones muy concretas que en nada afectan la conclusión que se viene analizando.

De esta forma, los potenciales perdedores que pudieran existir en el concurso no emanan de decisiones concursales de juego de suma cero. En efecto, al ser las reglas de titularidad de créditos exógenas al concurso, no existen decisiones concursales (ya sea del juez o de los órganos concursales de administración) por medio de las cuales los acreedores se encuentren en condiciones de ganar o perder. Por el contrario, dentro de los deberes de los órganos concursales se encuentran el respeto de las titularidades, preferencias y cuantía de los créditos de los acreedores, las que no deben ser alteradas, salvo acuerdo de estos o supuestos normativos de excepción.

Así, concurriendo los acreedores al concurso en los periodos de determinación de créditos, ellos deberán ser tratados de acuerdo con la ubicación de su privilegio. Si finalmente la cuantía de lo recibido es mayor o menor a lo que otros acreedores reciben, ello ocurrirá en función de dos factores. En primer lugar, en razón de los derechos que poseían los acreedores de acuerdo con reglas de Derecho Común no concursal y, en segundo lugar, por la cuantía del patrimonio del deudor para satisfacer sus créditos. De esta forma, a mayor privilegio y mayor valorización del patrimonio del deudor, mayor posibilidad de mejorar la tasa de recuperación. De tales factores, el único que es de interés del concurso es la valorización del patrimonio del deudor. Las reglas concursales, pretenden precisamente mejorar ese valor, para así aumentar la tasa de recuperación.

Pero esa actuación de maximización supone un juego de ganar-ganar para los acreedores. En la medida que el resultado de maximización se obtenga, los acreedores se encontrarán en mejores condiciones en términos de recuperación. Y dado que tales actuaciones de maximización están conformadas por un conjunto de decisiones concursales del juez, de los órganos concursales de administración y de los acreedores, es que no resulta posible entender que esas decisiones sean juegos de suma cero, donde lo que uno pierde, el otro lo gana. En otras palabras, las decisiones

${ }^{57}$ Así se ha señalado en Estados Unidos, véase WARREN (1997), pp. 1387-1390. Se hace presente que estas excepciones solamente existen en sistemas normativos donde se genera un estatuto de prelación concursal diverso del estatuto de Derecho Común. En España, por ejemplo, hay distintas clasificaciones y prelaciones de créditos entre la ejecución colectiva y la tutela individual. Ello originado por el no cumplimiento de lo establecido en la disposición final trigésimo tercera de la ley 22/2003, de 9 de julio. Esa norma que consagra un plazo para que el gobierno remita a las cortes un proyecto de ley reguladora de la concurrencia y prelación de créditos en caso de ejecuciones singulares, lo que no se ha cumplido, véase Rogel (2013), pp. 82-83. Tal situación no sucede en Chile al tener un régimen unificado de prelación con base en el Código Civil. 
concursales de maximización solo tienden a generar ganadores desde la perspectiva de la recuperación de créditos. El hecho que el proceso concursal, en razón de su lógica de mejora de la tasa de recuperación, conduzca a evitar la existencia de perdedores, trae consigo una reducción de la problemática de la comparación interpersonal.

Este problema constituye la crítica habitual a la aplicación judicial de la eficiencia, en cuanto a que existiría una imposibilidad de justificación moral a las pérdidas que sufren los perdedores de una decisión adoptada sobre la base de tales criterios, ya que no sería posible comparar los niveles de bienestar que dejan de recibir los perdedores en relación con las ganancias de bienestar de los ganadores ${ }^{58}$. Para afrontar tal problemática, Amartya Sen ha intentado establecer pautas de elección social que no incurran en los extremos de no comparabilidad ni comparabilidad completa. Ha propuesto introducir variabilidad limitada en las unidades de bienestar de diferentes sujetos y manejar, correspondencias de muchos a muchos, y no de uno a uno ${ }^{59}$. Con todo, tal propuesta no es aplicable al Derecho Procesal, porque el acto de adjudicación no permite ejercicios de comparabilidad parcial al enfrentarnos a dos sujetos (correspondencias de uno a uno, esto es, entre demandante y demandado). Sin embargo, tal propuesta de variabilidad limitada puede resultar perfectamente aplicable al Derecho Procesal Con72 cursal, toda vez que las correspondencias operan entre grupos que incluyen a un colectivo de sujetos, esto es, suponen correspondencias de muchos con muchos. Trataré de mostrar lo anterior en lo que sigue, dejando en claro que la idea subyacente es que la introducción de una pauta de variabilidad limitada en el Derecho Procesal Concursal (y, por tanto, desde la eficiencia concursal ex post), busca reducir los problemas de comparación interpersonal de utilidades, al aminorar la probabilidad de surgimiento de perdedores.

Amartya Sen ha señalado que es posible alcanzar comparabilidad parcial de utilidades en un ejercicio de "muchos contra muchos". Entendemos que tal comparabilidad es perfectamente aplicable en el Derecho Procesal Concursal, donde intervienen diferentes grupos de sujetos interesados. $\mathrm{Si}$ nos concentramos en los acreedores y en la mejora de la tasa de recuperación de sus créditos, podemos apreciar que el proceso concursal entrega un sustrato para realizar tales comparaciones parciales de utilidades entre distintas clases de acreedores. Esto constituye una razón para sostener la aplicación de la eficiencia en el Derecho Procesal Concursal, toda vez que, una de las críticas fundamentales a su procedencia (la imposibilidad de medir las variaciones de utilidad de los sujetos implicados), se encuentra atenuada cuando nos referimos a la eficiencia concursal ex post.

${ }^{58}$ Véanse los trabajos clásicos sobre el tema HaRSANYi (1955), pp. 317-320 y RoBbins (1932), pp. 123-124. Más actualmente Hausman y McPherson (2007), pp. 143-144.

${ }^{59}$ SEN (1976), pp. 126-130. 
Introduciendo sus ideas, Amartya Sen nos indica que el incendio provocado en Roma por Nerón significó un descenso en la suma del bienestar total respecto de la situación existente con anterioridad. Para llegar a esa conclusión no necesitamos especificar la manera en que se modificaron las correspondientes unidades de bienestar de cada romano respecto de cualquier otro. Sabremos, a ciencia cierta, que ocurrió un descenso en la suma del bienestar total, a pesar de no comparar las unidades de bienestar de cada ciudadano romano ${ }^{60}$. Similarmente, en el proceso concursal podremos llegar la conclusión de que existe una mejora en el bienestar si en el estado post concurso se mejora la tasa de recuperación que los acreedores tenían previo al concurso. Lo anterior, sin necesidad de indagar en los niveles individuales de bienestar de cada uno de los acreedores en ambos estados. Tampoco se necesita averiguar la manera en que se modifican esas variaciones de bienestar en relación con cada uno de los otros acreedores. Siguiendo el modelo de Amartya Sen de comparabilidad parcial ${ }^{61}$, procederemos de la forma siguiente.

Primeramente, en el escenario $\Omega$ agruparemos a los acreedores en tres categorías (ordinarios, privilegiados y trabajadores). En tal escenario compararemos las tasas de recuperación de los acreedores frente a tres subescenarios o estados sociales posibles (X/Y/Z). Cada uno de tales subescenarios posee tres distribuciones de bienestar para cada una de esas tres categorías de acreedores $(\mathrm{a} / \mathrm{b} / \mathrm{c})$. La idea en el escenario $\Omega$ es indagar acerca de cuál de las posibles distribuciones de bienestar es preferida estrictamente a las otras.

Posteriormente, en el escenario $\mho$ se aumentará al doble las dos peores distribuciones de bienestar de cada subescenario posible y se reducirá al doble la mejor distribución de bienestar de cada subescenario. La idea en el escenario $\mho$ es averiguar si procediendo de tal manera se mantiene la misma preferencia existente en la distribución de bienestar ocurrida en $\Omega$. De ser así, existirá una distribución de bienestar preferida a otras, en dos escenarios de comparabilidad de "muchos con muchos", y, por tanto, estaremos frente a una distribución de bienestar que debe ser preferida socialmente.

La idea es concluir que de mantenerse en $\mho$ la preferencia en la distribución de bienestar de $\Omega$ entonces, existirá una distribución de tasas de recuperación que debe ser aceptada socialmente. Tal distribución preferida es aquella que aumenta la tasa de recuperación crediticia a favor de los acreedores.

Primer escenario $(\Omega)$. La distribución de bienestar para los tres grupos de participantes en cada uno de los estados sociales analizados es:

${ }^{60} \mathrm{SEN}$ (1976), p. 126.

${ }^{61}$ Op. cit., pp. 126-130; 136-138. 
Tabla 1:

Distribución de bienestar en $\Omega$

\begin{tabular}{|c|c|c|c|}
\hline & Ordinario & Privilegiados & Trabajadores \\
\hline $\mathrm{X}$ & 5 & 0,1 & 0,8 \\
\hline $\mathrm{Y}$ & 0,2 & 1 & 0,5 \\
\hline $\mathrm{Z}$ & 0,6 & 0,22 & 0,6 \\
\hline
\end{tabular}

Reformulación de SEN (1976), pp. 127-130.

De la tabla anterior podemos sacar las siguientes conclusiones:

i) El subescenario social que aumenta la tasa de bienestar social total es X;

ii) El estado social $\mathrm{X}$ es preferido por ordinarios y trabajadores;

iii) La preferencia de los privilegiados debe ser por el estado social Y, el que constituye el peor subescenario para los ordinarios y para los trabajadores;

iv) El estado social Z es el segundo mejor estado social para cada uno de los acreedores y

v) Ninguno de los estados sociales alcanza a constituirse en un escenario superior a Pareto.

En efecto, no será aceptado el tránsito de cualquier acreedor desde el estado social preferido por ellos al resto de los estados sociales.

A partir de tales conclusiones tenemos que el estado social que es estrictamente preferido es $\mathrm{X}(\mathrm{X}>\mathrm{Y}>\mathrm{Z})$. Lo anterior se demuestra comparando cada uno de esos estados sociales entre sí para cada uno de los grupos de acreedores:

Tabla 2:

Comparación de estados sociales por grupos de acreedores en $\Omega$

\begin{tabular}{|c|c|c|c|}
\hline & Ordinarios & Privilegiados & Trabajadores \\
\hline X, Y & 4,8 & $-0,9$ & 0,3 \\
\hline Y, Z & $-0,4$ & 0,78 & $-0,1$ \\
\hline Z, X & $-4,4$ & 0,12 & $-0,2$ \\
\hline
\end{tabular}

Reformulación de SEN (1976), pp. 127-130.

De tal tabla tenemos que la variabilidad de bienestar social entre cada uno de los estados sociales en comparación al otro determina la preferencia $(\mathrm{X}>\mathrm{Y}>\mathrm{Z})$, según el siguiente examen: 
i) Preferencia $\mathrm{X}$ en la comparabilidad X/Y: En efecto, si comparamos la variabilidad de unidades de bienestar de cada grupo respecto de los estados sociales $\mathrm{X} / \mathrm{Y}$, tendremos que el bienestar asociado al estado social $\mathrm{X}$ (4,8 para ordinarios $+0,3$ para trabajadores $=5,1)$, supera al del estado social Y (0,9 para privilegiados). De forma que: $\mathrm{X}>\mathrm{Y}$;

ii) Preferencia Y en la comparabilidad Y/Z: Si comparamos la variabilidad de unidades de bienestar de cada grupo respecto de los estados sociales $\mathrm{Y} / \mathrm{Z}$, tendremos que el bienestar asociado al estado social Y (0,78 para privilegiados), supera al del estado social Z $(0,4$ para ordinarios $+0,1$ para trabajadores $=0,5)$. De forma que $\mathrm{Y}>$ Z;

iii) Preferencia $\mathrm{X}$ en la comparabilidad $\mathrm{Z} / \mathrm{X}$ : Si comparamos la variabilidad de unidades de bienestar de cada grupo respecto de los estados sociales $\mathrm{Z} / \mathrm{X}$, tendremos que el bienestar asociado al estado social $\mathrm{X}(4,4$ para ordinarios $+0,2$ para trabajadores $=$ $6,6)$, supera al del estado social Z (0,12 para los privilegiados). De forma que $\mathrm{X}>\mathrm{Z}$.

Como resumen de la comparabilidad de estados sociales $\mathrm{X} / \mathrm{Y} / \mathrm{Z}$ en relación con variabilidad de unidades de bienestar respecto de cada grupo de intervinientes en el primer escenario $\Omega$ tendremos que en el primer escenario $\Omega$ el estado social X es preferido estrictamente a Y; Y es preferido estrictamente al estado social $\mathrm{Z}$, y finalmente, $\mathrm{X}$ es preferido estrictamente a Z. De forma que para el examen de los tres estados sociales: $\mathrm{X}>\mathrm{Y}>\mathrm{Z}$.

Procederemos ahora de la forma señalada precedentemente para ver si tal resultado se mantiene en el segundo escenario $\mho$.

Segundo escenario $\mho$, con la finalidad de averiguar si se mantiene la misma preferencia determinada por la distribución de bienestar ocurrida en $\Omega$, es que procederemos a aumentar al doble las dos peores distribuciones de bienestar de cada subescenario posible en $\Omega$, así como reducir al doble la mejor distribución de bienestar de cada subescenario en $\Omega$. De esta forma, la nuevo tabla de distribución de bienestar entre los distintos grupos de participantes para los tres estados sociales posibles es:

Tabla 3:

Distribución de bienestar en $\mho$

\begin{tabular}{|c|c|c|c|}
\hline & Ordinarios & Privilegiados & Trabajadores \\
\hline $\mathrm{X}$ & 2,5 & 0,2 & 0,4 \\
\hline $\mathrm{Y}$ & 0,4 & 0,5 & 1 \\
\hline $\mathrm{Z}$ & 1,2 & 0,44 & 1,2 \\
\hline
\end{tabular}

Reformulación de SEN (1976), pp. 127-130. 
Como conclusiones de esta nueva distribución de bienestar tenemos que:

i) Se mantiene la preferencia estricta de $\mathrm{X}$ respecto del resto de los subescenarios sociales. Lo anterior, porque el bienestar social agregado de $\mathrm{X}$ alcanza a 3,1 unidades de bienestar; Y alcanza 1,9 unidades de bienestar agregado; $\mathrm{Z}$ alcanza 2,84 unidades de bienestar agregado;

ii) El estado social $\mathrm{X}$ es el preferido estrictamente por los acreedores ordinarios al igual como sucedía en $\Omega$. Por otro lado, se mejoran los niveles de preferencia respecto de este estado por los privilegiados en relación con lo que sucedía en $\Omega$;

iii) El estado social Y subsiste como el subescenario preferido estrictamente por los privilegiados. Para los trabajadores, el estado social Y pasa a ser el segundo el subescenario más preferido. Para los ordinarios sigue siendo el subescenario menos preferido.

iv) Respecto del estado social Z, sigue siendo el segundo estado social preferido para los ordinarios y privilegiados. Se mantiene como el segundo mejor subescenario social para los trabajadores, y

v) Ninguno de los estados sociales alcanza a constituirse en un subescenario superior a Pareto, ya que no será aceptado el tránsito de cualquier acreedor desde el estado social preferido por ellos al resto de los estados sociales.

A partir de tales conclusiones tenemos que el estado social que es estrictamente preferido es X. Sin embargo, veremos que la comparación entre $\mathrm{Y} / \mathrm{Z}$, presenta algunas diferencias respecto de lo sucedido en $\Omega$. Lo que, con todo, no impide considerar que $\mathrm{X}$ debe ser aceptado como el escenario social que mejora la tasa de recuperación de los acreedores y, por ende, la eficiencia concursal ex post. Ello se demuestra comparando cada uno de esos estados sociales entre sí para cada uno de los grupos de acreedores:

Tabla 4:

Comparación de estados sociales por grupos de acreedores en $\mho$

\begin{tabular}{|c|c|c|c|}
\hline & Ordinarios & Privilegiados & Trabajadores \\
\hline $\mathrm{X}, \mathrm{Y}$ & 2,1 & $-0,3$ & $-0,6$ \\
\hline $\mathrm{Y}, \mathrm{Z}$ & $-0,8$ & 0,06 & $-0,2$ \\
\hline $\mathrm{Z}, \mathrm{X}$ & $-1,3$ & 0,22 & $-0,84$ \\
\hline
\end{tabular}

Reformulación de SEN (1976), pp. 127-130. 
De tal tabla tenemos que la variabilidad de bienestar social entre cada uno de los estados sociales en comparación al otro determina la preferencia $(\mathrm{X}<\mathrm{Z}<\mathrm{Y})$ según el siguiente examen:

i) Preferencia $X$ en la comparabilidad X/Y: En efecto, si comparamos la variabilidad de unidades de bienestar de cada grupo respecto de los estados sociales $\mathrm{X} / \mathrm{Y}$, tendremos que el bienestar asociado al estado social X (2,1 para ordinarios), supera al del estado social $\mathrm{Y}$ (0,3 para privilegiados $+0,6$ para los trabajadores). De forma que: $\mathrm{X}>\mathrm{Y}$;

ii) Preferencia $Z$ en la comparabilidad $Y / Z$ : En efecto, si comparamos la variabilidad de unidades de bienestar de cada grupo respecto de los estados sociales $\mathrm{Y} / \mathrm{Z}$, tendremos que el bienestar asociado al estado social $Z(0,8$ para ordinarios $+0,2$ para trabajadores $=1)$, supera al del estado social Y (0,06 para privilegiados). De forma que: $\mathrm{Z}>\mathrm{Y}$;

iii) Preferencia $X$ en la comparabilidad Z/X: Si comparamos la variabilidad de unidades de bienestar de cada grupo respecto de los estados sociales $\mathrm{Z} / \mathrm{X}$, tendremos que el bienestar asociado al estado social $\mathrm{X}(1,3$ para ordinarios $+0,8$ para trabajadores $=1,8)$, supera al del estado social $\mathrm{Z}$ (0,22 para los privilegiados). De forma que $\mathrm{X}>\mathrm{Z}$.

Como resumen de comparabilidad de estados sociales $\mathrm{X} / \mathrm{Y} / \mathrm{Z}$ en relación con variabilidad de unidades de bienestar respecto de cada grupo de intervinientes en el segundo escenario $\mho$ tenemos que en el primer escenario $\mho$ el estado social $\mathrm{X}$ es preferido estrictamente a $\mathrm{Y}$; Z es preferido estrictamente al estado social $\mathrm{Y}, \mathrm{y}$ finalmente, $\mathrm{X}$ es preferido estrictamente a $\mathrm{Z}$. De forma que para el examen de los tres estados sociales: $\mathrm{X}>\mathrm{Z}>\mathrm{Y}$.

Resumen del primer escenario $(\Omega)$ y del segundo escenario $(\mho)$ y conclusiones: Según hemos examinado, en el primer escenario las preferencias estrictas de los estados sociales por los distintos grupos de acreedores, era: $\mathrm{X}>\mathrm{Y}>\mathrm{Z}$. En cambio, en el segundo escenario las preferencias estrictas de los estados sociales por los distintos grupos de acreedores, era: $\mathrm{X}>\mathrm{Z}>\mathrm{Y}$.

De esta forma, entre ambos escenarios existe una diferencia respecto de las preferencias para el segundo y tercer mejor lugar. Con todo, en ambos casos, las preferencias estrictas por el estado social X son evidentes. Tal estado social es el que aumenta la tasa de recuperación crediticia y, por tanto, permite alcanzar la eficiencia concursal ex post, sin que sea necesario realizar un examen de comparabilidad de las variaciones de unidades de bienestar de cada acreedor en relación con los otros. De esta forma, es posible en el proceso concursal alcanzar una conclusión respecto de un mejor estado social sin afrontar problemas de comparación interpersonal de utilidades. 


\section{En el Derecho Procesal Concursal se justifica la eficiencia EN LAS PREFERENCIAS DE LOS SUJETOS QUE PARTICIPAN DEL CONCURSO}

Finalmente, y como tercera razón para justificar la eficiencia en el Derecho Procesal Concursal tenemos que el foro del concurso constituye un contexto de decisión donde es factible justificar la eficiencia en las preferencias de los sujetos que allí intervienen ${ }^{62}$. Hemos señalado que uno de los supuestos de aplicación de la reponsividad no negativa corresponde al subconjunto normativo concursal. Existirá supuestos de responsividad no negativa ${ }^{63}$, cuando para cualquier individuo de una sociedad la alternativa $\mathrm{X}$ (digamos, "mayor bienestar social"), no cede frente a la alternativa Y (digamos, "cualquier otra opción distinta a mayor bienestar social"), de forma que tampoco para la sociedad, la alternativa $\mathrm{X}$ cede frente a la alternativa $\mathrm{Y}$.

Cabe señalar que la responsividad no negativa satisface exigencias de aciclicidad, esto es, si la alternativa $X_{1}$ es preferida a $X_{2}, X_{2}$ a $X_{3,}$ y así sucesivamente hasta, entonces, la aciclicidad exige que $\mathrm{X}_{1}$ sea considerada al menos tan buena como $\left(\mathrm{X}_{1}\right.$

La aciclicidad es una condición más tenue que la transitividad. Esta última supone una preferencia estricta entre ternas, de forma que si $\mathrm{X}_{1}$ es preferida a $\mathrm{X}_{2}, \mathrm{y} \mathrm{X}_{2}$ es preferida a $\mathrm{X}_{3}$, entonces, $\mathrm{X}_{1}$ es preferida a $\mathrm{X}_{3}$ En términos tales que si se cumple tal transitividad en la totalidad de las termas, entonces, la transitividad se cumple para todo el conjunto ${ }^{64}$. En este sentido si, $\mathrm{x}_{1} \mathrm{P} \mathrm{x}_{2}$, representa una relación binaria según la cual " $\mathrm{x}_{1}$ prefiere en un subconjunto $\mathrm{P}$ a $\mathrm{x}_{2}$ " en el contexto de un conjunto $\mathrm{S}$, tendremos que: para todo $\mathrm{X}_{1}, \mathrm{X}_{2}$ y $\mathrm{X}_{3}$ perteneciente al conjunto $\mathrm{S}$ : $\left(\mathrm{x}_{1} \mathrm{P}\right.$ $\left.\mathrm{x}_{2} \& \mathrm{x}_{2} \mathrm{P}_{3}\right) \mathrm{x}_{1} \mathrm{P} \mathrm{x}_{3}$.

Sin embargo, una relación de preferencia puede ser acíclica sobre todas las ternas, pero infringir la aciclicidad en el conjunto. Por ejemplo, supongamos que tenemos dos personas en una sociedad (A y B), y las preferencias de A sobre los estados sociales alternativos es: $\mathrm{X}>\mathrm{Y}$ Y $>$ $Z$; en circunstancias que las preferencias de $B$ sobre esos mismos estados sociales alternativos es: $\mathrm{Y}>\mathrm{Z} \mathrm{Z}>\mathrm{X}$. En este caso, en el par (Y, Z), Y es

${ }^{62}$ Por el contrario, se ha argumentado que la normativa de insolvencia no es el resultado de la aplicación de principios formulados por un legislador racional, que se extienden por toda la legislación concursal, véase CARLSON (1987), pp. 1341-1389. Esa argumentación es una crítica a la explicación económica del concurso porque ella se basa en la lógica unificadora que posee la eficiencia. Sin embargo, la perspectiva de eficiencia no se sostiene en una idea de racionalidad fuerte, sino que descansa en las motivaciones de los sujetos, tal como se pretende explicar en este acápite y como se ha expuesto en Carrasco (2017), pp. 185-208.

${ }^{63} \operatorname{SEN}(1976)$, p. 91.

${ }^{64}$ Op. cit., pp. 65-66. 
socialmente preferida a $\mathrm{Z}$ (ello ocurre tanto según las preferencias de $\mathrm{A}$ y B), pero en los pares $(X, Y)$ y $(X, Z)$, existe situación de indiferencia ${ }^{65}$ (ello debido a que no existe una preferencia estricta de A y B respecto de esos pares). Con todo, en este ejemplo, tenemos una mejor alternativa en cada subconjunto ( $\mathrm{Y}>\mathrm{Z}$, tanto para A como para B), pero no sobre el total (preferencias de A y B sobre las alternativas X, Y y Z) ${ }^{66}$.

Pues bien, de acuerdo con lo que hemos desarrollado, es un interés reconocido por el legislador que el proceso concursal tienda a mejorar la recuperación de los créditos. Lo anterior, justifica su existencia frente a las alternativas de tutela individual. De esta forma, si se declara el inicio de un concurso, y nosotros enfrentamos a los acreedores a un escenario futuro donde le indicamos que la tasa de recuperación es \$ 100 (escenario $\mathrm{X}_{1}$ ), y otro escenario donde la tasa de recuperación es \$200 (escenario $\mathrm{X}_{2}$ ), es altamente probable, que los acreedores escogerán el escenario $\mathrm{X}_{2}$. Lo que en términos de la relación binaria anterior, significa que: $\mathrm{x}_{2} \mathrm{P} \mathrm{x}_{1}$.

Incluso, en el improbable caso que los acreedores no prefieran estrictamente $\mathrm{X}_{2}$, es difícil concebir que $\mathrm{X}_{2}$ no sea considerado al menos tan bueno como $\mathrm{X}_{1}$, tomando en cuenta todos los factores relevantes que pudieran ser de importancia para los acreedores. De esta forma, tendremos que: $\mathrm{X}_{2} \mathrm{X}_{1}$, adquiere al menos algún valor para tales acreedores.

Según vimos en el ejemplo del cramdown, en la legislación estadounidense la imposición a los acreedores disidentes de un plan de reorganización en aquellos supuestos en los cuales se les asegura una tasa de recuperación idéntica a la que obtendrían en un procedimiento de liquidación demuestra la existencia de un interés social en llevar a cabo la solución concursal de la reorganización. En ello subyace que la finalidad es asegurar la mayor tasa de recuperación que surja de ambos procedimientos. Así, el recupero en el plan de reorganización al ser tan bueno (responsividad no negativa) como el recupero de la liquidación, conduce a la imposición de este último procedimiento. En otras palabras, si ello es valorado como algo al menos tan bueno para los disidentes, entonces, lo es también para la sociedad como un todo (representada en la labor del juez que aplica la institución del cramdown).

Para Amartya Sen, la aciclicidad da lugar a reglas de elección colectivas que permiten determinar una mejor decisión en subconjuntos determinados. Uno de tales subconjuntos puede ser aquellos subconjuntos

${ }^{65}$ SEN (1976), p. 67.

${ }^{66} \mathrm{Si}$ la alternativa preferida implica el tránsito de un estado social a otro (que es superior a Pareto respecto del primero) se debe valorar el efecto de certidumbre que pudiera afectar a los sujetos A y B. Ese efecto pudiera implicar que la alternativa eficientemente preferida no lo sea para ese sujeto en particular, en la medida que (probabilísticamente) exista alguna posibilidad de pérdida, véase KAHNEMAN et al. (1986), pp. 728-741. 
normativos que hemos identificado donde opera la eficiencia (Derecho Procesal Concursal). En este sentido, una decisión judicial adoptada en subconjuntos que tiendan hacia la eficiencia, puede entregar una mejor decisión en ese contexto. Con todo, ello no significa que esa regla de elección colectiva aplique en todo el conjunto, por ejemplo, a la totalidad del sistema jurídico. Esto es relevante porque permite fundamentar mejores decisiones sobre la base de determinadas reglas de elección social (como la eficiencia), en ciertos subconjuntos normativos, sin que se imponga la necesidad lógica-jurídica de buscar un único factor que permita resolver los conflictos que surjan en el sistema jurídico como un todo.

Las mencionadas tres razones expresan la justificación de la eficiencia como un valor presente en el Derecho Procesal Concursal, concretizada en la eficiencia concursal ex post.

\section{Conclusiones}

Producida una situación de acción colectiva de acreedores es deseable generar la mayor tasa de recuperación a favor de los acreedores como un todo. Tal objetivo expresa una necesidad de incremento de riqueza que es insatisfactoriamente enfrentado por la tutela individual. Por su parte, tal finalidad se reconduce adecuadamente a lo que se ha denominado eficiencia concursal ex post, que opera en el concurso. En este artículo se ha buscado precisar y resaltar las razones que subyacen a la afirmación que la eficiencia es un valor presente en el Derecho Procesal Concursal. En este sentido, una serie de instrumentos en tal área jurídica buscan, precisamente, incrementar la masa pasiva para permitir una mayor recuperación de los acreedores. Tales instrumentos se encuentran ausentes en la tutela individual y en la lógica que sustenta el principio prior tempore, potior iure. Asimismo, en el concurso las reglas de titularidad son respetadas en lo indispensable para el tratamiento de la acción colectiva de los acreedores. Al respecto, el concurso se configura como un escenario donde es posible variabilidad limitada en las unidades de bienestar de diferentes sujetos y manejar, correspondencias de "muchos a muchos". Finalmente, podemos recurrir a la eficiencia como un criterio de decisión que surge de la mismas preferencias de los sujetos que participan en el concurso, quienes razonablemente querrán que en tal subconjunto normativo existan decisiones que busquen mejorar los niveles de riqueza (recuperación de créditos). Sobere la base de lo examinado resulta difícil identificar un factor distinto de la eficiencia que pueda satisfacer adecuadamente el objetivo mencionado. Invito a discutir las conclusiones aquí expuestas. 


\section{Bibliografía CitADA}

AdLer, Barry \& Ian Ayres (2001-2002). "A Dilution Mechanism for Valuing Corporations in Bankruptcy". The Yale Law Journal. Vol. 111, N 1 . New Haven.

Alonso, Carmen (2016). "Los modelos de administración concursal", en Ángel Rojo, Esperanza Gallego y Ana Campuzano (dirs.). La administración concursal. VII Congreso Español de Derecho de la Insolvencia. Madrid: Thomson Reuters-Civitas.

ANG, James y Jess ChuA (1980). "Coalitions, the Me-First Rule, and the Liquidation Decision". The Bell Journal of Economics. Vol. 11, No 1 . New Haven.

Armstrong, Vaughn \& Riddick, Leigh (2003). Bankruptcy Law Differences Across Countries, Managerial Incentives and Firm Value. Disponible en http://papers. ssrn.com/sol3/papers.cfm?abstract_id=420560 [fecha de consulta: 2 de noviembre de 2016].

BAIRD, Douglas (1987). "Loss distribution, fórum shopping and bankruptcy: a reply to Warren". University of Chicago Law Review. No 54 . Chcago.

BAIRD, Douglas (1986). "The Uneasy Case for Corporate Reorganizaction”. Journal of Legal Studies. $\mathrm{N}^{\circ} 15$. Chicago.

BeвCHUCK, Lucian (2002). "Ex ante costs of violating: Absolute Priority in Bankruptcy". Journal of Finance. Vol. 57. Aldan, Pennsylvania.

Berkovitch, Elazar \& Ronen Israel (1999). "Optimal bankruptcy laws across different economic systems”. Review of Financial Studies. Vol. 12, № 2. Oxford.

Bisogno, Marco \& Roberto DE LuCA (2014). "Bankruptcy Efficiency and Indirect Cost in Italian SMEs: a Temporal Approach". International Journal of Business Research and Development. Vol. 3, No 2. Otawa.

CABRILlo, Francisco (1989). Quiebra y liquidación de empresas. Madrid: Unión Editorial.

Carapeto, María (2000). "Is bargaing in Chapter 11 costly?". Working Paper, London City University Business School. London.

CARLson, David (1987). "Review: Philosophy in Bankruptcy: The Logic and Limits of Bankruptcy Law by Thomas H. Jackson". Michigan Law Review. Vol. 85, $\mathrm{N}^{\mathrm{o}}$ 5-6. Michigan

Carlson, David (1989). "Postpetition Interest Under the Bankruptcy Code". University of Miami Law Review. Vol. 43. Miami.

CARRASCO, Nicolás (2012). "Análisis económico del derecho de la tutela cautelar en la legislación civil en Chile". Revista de Derecho. Escuela de Posgrado. No 2. Santiago.

CARRASCO, Nicolás (2016a). "El forum shopping y la legislación chilena sobre acción colectiva de los acreedores". Revista de derecho Pontificia Universidad Católica de Valparaíso. № 4 . Valparaíso.

CARRASCo, Nicolás (2016b). "El óptimo de justicia procesal concursal en las subastas electrónicas: ¿Cómo podemos obtener una mayor tasa de recuperación 
en los procesos concursales", en Federico Bueno de Mata (coord.): Fodertics 5.0 estudios sobre nuevas tecnologías y justicia. Granada: Editorial Comares.

Carrasco, Nicolás (2017). "La eficiencia procesal y el debido proceso". Revista de Derecho Privado. No 32. Santiago.

CARrasco, Nicolás (2017). "El proceso civil como juego no repetitivo y como vía para interiorizar cargas informativas: Una mirada desde el análisis económico del derecho". Revista Chilena del Derecho. Vol. 44, No 1. Santiago.

Concha, Carlos (1971). El proceso de quiebras. Valparaíso: Editorial López Vivanco.

Elster, Jon (2009). "Excessive Ambitions". Capitalism and Society. Vol. 4, No 2. New York.

ELSTER, Jon (1997). EGOnomics. Barcelona: Gedisa.

Eremenko, Paul (2005). When Fairness is Efficient: The role of the Judiciary in Maximing Aggregate Social Welfare. Disponible en http://ssrn.com/abstract=900463. [fecha de consulta: 6 de noviembre de 2015].

Gertner, Robert \& David Scharfstein (1991). "A Theory of Workouts and the Effects of Reorganization Law". Journal of Finance. Vol. 46. Aldan, Pennsylvania.

Goldenberg, Juan Luis (2013a). "Bases para la privatización del derecho concursal. Revista Chilena de Derecho Privado. No 20. Santiago.

Goldenberg, Juan Luis (2013b). "Las Motivaciones del Voto en el Concurso de Acreedores (In Re DBSD North America, Inc. 634 F.3D 79 2011)". Revista de Derecho Universidad Católica del Norte. Año. 20, N 1 . Antofagasta.

GonZÁLEz, Emilio (2005). "Identificación de los intereses concurrentes y del interés del concurso en la nueva ley concursal", en Estudios sobre la ley concursal. Libro homenaje a Manuel Olivencia. Madrid: Marcial Pons, tomo II.

Gross, Karen (1997). Failure and Forgiveness: Rebalancing the Bankruptcy System. New Haven: Yale University Press.

GurreA, Aurelio (2014). "La incomprensible preferencia del convenio a la liquidación como solución del concurso de acreedores", en Ángel Rojo, Jesús Quijano y Ana Campuzano (dirs.). La liquidación de la masa activa. VI Congreso Español del Derecho de la Insolvencia. Cizur-Menor: Thomson Reuters-Civitas.

HARSANY, John (1995). "Cardinal Welfare, Individualistic Ethics and Interpersonal Comparison of Utility". The Journal of Political Economy. Vol. 63, № 4. Chicago.

HaRT, Oliver (1995). Firms, Contracts y Financial Structure, Oxford: Claredon Press.

Hausman, Daniel y Michael McPherson (2007). El análisis económico y la filosofía moral. México DF: Fondo de Cultura Económica.

Hicks, Jonathan (2005). "Foxes Guarding The Henhouse: The modern best interests of creditors test in Chapter 11 Reorganization". Nevada Law Journal. Vol. 5. Las Vegas, Nevada.

Hirschman, Albert (1986). Interés privado y acción pública. México D.F: Fondo de Cultura Económica. 
Hunter, Iván (2010). "El principio dispositivo y los poderes del juez". Revista de Derecho de la Pontificia Universidad Católica de Valparaíso. No 35. Valparaíso.

Jackson, Thomas (1982). "Bankruptcy, Non-Bankruptcy Entitlements, and the Creditors" Bargain”. The Yale Law Journal. Vol. 91, N 5. New Haven.

JACKson, Thomas (1985). "The Logic and Limits of Bankruptcy Law”. Discussion Paper Program in Law and Economics Harvard Law School. No 16. Boston.

Jackson, Thomas \& Robert ScotT (1989). "On the Nature of Bankruptcy: An Essay on Bankruptcy Sharing and the Creditor's Bargain". Virginia Law Revierw. Vol. 75, No 2. Virginia.

Kahneman, Daniel \& Amos Tversky (1984). "Choices, Values, and Frames". American Psychologist. Vol. 39, $\mathrm{N}^{\circ}$ 4. Washington.

Kahneman, Daniel; Jack Knetsch \& Richard Thaler (1986). "Fairness as a Constraint on Profit Seeking: Entitlements in the Market". The American Economic Review. Vol. 76, No 4. Nashville.

KALDOR, Nicholas (1939). "Welfare Propositions of Economics and Interpersonal Comparisons of Utility". The Economic Journal. Vol. 49, No 195. London.

Kolnhauser, Lewis (1980). "A Guide to the Perplexed Claims of Efficiency in the Law". Hofstra Law Review. Vol. 8, No 3. New York.

Korobkin, Donald (1993). "Rehabilitating values: a jurisprudence of Bankruptcy". Columbia Law Review. Vol. 91, N. 4. New York.

La Porta, Rafael; Florencio LóPez-De-Silanes; Andrei Shleifer \& Robert Vishny (1998). "Law and Finance". Journal of Political Economy. Vol. 106, № 6. Chicago.

Levitin, Adam (2012). "Bankruptcy Politics and the Politics of Bankruptcy". Cornell Law Review. Vol. 97. New York.

Longhofer, Stanley \& Stephen Peters (2004). "Protection for whom? Creditor conflict and Bankruptcy". American Law and Economic Review. Vol. 6, № 2. New York.

Miller, Harvey \& Shai Waisman (2005). "Is Chapter 11 Bankrupcty?". Boston College Law Review. Vol. 47. Boston.

Marinc, Matej \& Razvan VLAHU (2012). The Economics of Bank Bankruptcy Law. Berlin: Springer-Verlag.

Markell, Bruce (1991). "Owners, Auctions, and Absolute Priority in Bankruptcy Reorganizations”. Stanford Law Review. Vol. 44. Stanford.

NúÑEz, Raúl y Francisco OrTíz (2014). "La aprobación judicial de los convenios concursales", en Nicolás CARRASCO y Raúl NúÑEZ (coords.). Presente y futuro del Derecho procesal concursal chileno. Una revisión desde el análisis económico del derecho. Santiago: Editorial Legal Publishing.

Peinado, Juan Ignacio (2006). "Cooperación y pillaje en el concurso". Estudios de Derecho Concursal. Madrid: Marcial Pons.

Pérez del Blanco, Guillermo (2007). Efectos procesales de la declaración del concurso: la vis attractiva concursal. Madrid: Editorial Reus. 
Posner, Richard (1997). El Análisis Económico del Derecho. México DF: Fondo de Cultura Económica.

Posner, Richard (1999). "Maximización de la Riqueza y Tort Law: Una investigación filosófica". Apuntes de derecho, $\mathrm{N}^{\mathrm{o}}$ 5, Santiago: Facultad de Derecho Universidad Diego Portales.

Posner, Richard (1998). "Utilitarismo, Economía y Teoría del Derecho”. Revista Estudios Públicos. N 69.

Povel, Paul (1999). “Optimal Soft or Tough Bankruptcy Procedures”. The Journal of Law, Economics y Organization. Vol. 15, No 3 .

Pulgar, Juana (2013). "Refinanciación de deuda: Un enfoque contractualista versus concursalista de la insolvencia", en Francisco ARIAS (ed.). Conservación de empresas en crisis: Estudios jurídicos y económicos. $\mathrm{N}^{\circ}$ 17. Madrid: La Ley

Rasmussen, Robert (1994). "Ex Ante Effects of Bankruptcy Reform”. Washington University Law Quarterly. Vol. 72, No 3. Washington.

Roвbins, Lionel (1932). An Essay on the Nature and Significance of Economic Science. Londres: Macmillan \& CO., Limited.

Rogel, Carlos (2013). Derecho de obligaciones y contratos. $2^{\text {a }}$ ed. Madrid: Editorial Reus.

Schwartz, Alan (1998). "A Contract Theory Approach to Business Bankruptcy". The Yale Law Journal. Vol. 107. New Haven.

SEn, Amartya (1976). Elección colectiva y bienestar social. Madrid: Alianza Editorial.

VeIga, Abel (2013). Par condicio omnium creditorum e insolvencia: Entre mito y la realidad utópica. Bogotá: Academia Colombiana de Jurisprudencia.

VoIGt, Stefan (2016). "Determinants of judicial efficiency: a survey". European Journal of Law and Economics. Vol. 42.

Warren, Elizabeth (1997). "Making Policy with Imperfect Information: The article 9 Full Priority Debates". Cornell Law Review. Vol. 82, № 6.

WArren, Elizabeth (1987). "Bankruptcy Policy". The University of Chicago Law Review. vol. 53, $\mathrm{N}^{\mathrm{O}}$ 3. Chicago.

Warren, Elizabeth \& Jay Westbrook (2005). Contracting Out of Bankruptcy: An Empirical Intervention.. Disponible en http://ssrn.com/abstract=901233 [fecha de consulta: 21 de diciembre de 2016].

White, Michelle (1980). "Public Policy toward Bankruptcy: Me-First and Other Priority Rules". The Bell Journal of Economics. vol. 11, N 2. New Haven.

Wohlschlegel, Ansgar (2002). The Economics of Corporate Bankruptcy Law. Disponible en http://d-nb.info/96600664X/34. [fecha de consulta 10 de agosto de 2017].

\section{Normas citadas}

Ley $\mathrm{N}^{0}$ 20.720, sustituye el régimen concursal vigente por una ley de Reorganización y Liquidación de empresas y personas, y perfecciona el rol de la Superintendencia del ramo. Diario Oficial, 9 de enero de 2014. 
Legge fallimentare, Regio decreto 16 de marzo de 1942, n. 267. Texto coordinado en el D.L. 3 de mayo de 2016, n. 59, convertido, con modificaciones en la L. 30 de junio de 2016, n. 119 y en la L. 11 de diciembre de 2016, n. 232.

Ley 22/2003, de 9 de julio, Concursal. Publicado en BOE, $\mathrm{N}^{\circ} 164$, de 10 de julio 2003.

Propuesta de Directiva del Parlamento Europeo y del Consejo "Sobre marcos de reestructuración preventiva, segunda oportunidad y medidas para aumentar la eficacia de los procedimientos de condonación, insolvencia y reestructuración, y por la que se modifique la Directiva 2012/30/UE” [COM (2016) 723 final; 2016/0359 (COD)]. 